\title{
A INTERNET COMO INSTRUMENTO DO ATIVISMO POPULAR DEMOCRÁTICO
}

\section{INTERNET AS AN INSTRUMENT OF DEMOCRACTIC POPULAR ACTIVISM}

\section{IVO DANTAS}

Professor Titular da Faculdade de Direito do Recife - UFPE. Doutor em Direito Constitucional - UFMG. Livre Docente em Direito Constitucional - UERJ. Livre Docente em Teoria do Estado - UFPE. Membro da Academia Brasileira de Letras Jurídicas. Membro da Academia Brasileira de Ciências Morais e Políticas. Presidente do Instituto Pernambucano de Direito Comparado. Presidente da Academia Pernambucana de Ciências Morais e Políticas. Miembro del Instituto IberoAmericano de Derecho Constitucional México). Miembro del Consejo Asesor del Anuario IberoAmericano de Justicia Constitucional, Centro de Estudios Políticos y Constitucionales (CEPC), Madrid. Ex- Diretor da Faculdade de Direito do Recife - UFPE. Membro da Academia Pernambucana de Letras Jurídicas. Fundador da Associação Brasileira dos Constitucionalistas Democráticos. Membro Efetivo do Instituto dos Advogados de Pernambuco. Membro do Instituto Pimenta Bueno - Associação Brasileira dos Constitucionalistas. Professor Titular de Processo Constitucional na Faculdade de Olinda (FACO), Pernambuco. Ex-Professor Orientador Visitante do Programa de PósGraduação em Ciências da Saúde, Universidade Federal do Rio Grande do Norte, conforme aprovação do Colegiado, em 31 de maio de 2001. Ex-Professor do Curso de Mestrado em Direito da Universidade da Amazônia, UNAMA, Belém do Pará. Juiz Federal do Trabalho (aposentado). Advogado e Parecerista. E-mail: profivodantas@uol.com.br 


\section{ANA CÉLIA DE SOUSA RIBEIRO}

Doutoranda em Direito pela UFPE. Mestre em Direito pela UFPE. Especialista em Direito Civil e Processo Civil pela Escola Superior de Advocacia em Pernambuco (ESA/PE). Especialista em Direito Constitucional pelo Complexo Educacional Damásio de Jesus. Analista Judiciária - Área Judiciária - da Justiça Federal em Pernambuco. E-mail: anaceliasribeiro@hotmail.com.

\section{RESUMO}

Objetivo: Esta pesquisa tem por meta analisar a Internet como um relevante instrumento do ativismo popular, capaz de fortalecer o regime político democrático, possibilitando um nascente ativismo popular que abre novas fronteiras, dentre elas a perspectiva de uma maior mobilização popular, além de uma mais efetiva interferência na formação da opinião pública.

Metodologia: O trabalho foi norteado por uma pesquisa jurídica de cunho dogmático, utilizando-se o método dedutivo, desenvolvido através de pesquisa bibliográfica, por meio, principalmente, de livros especializados e de artigos de revista.

Resultados: É possível afirmar, como conclusão desta pesquisa, que a democracia semidireta representa uma abertura para o ativismo popular, que vem fortalecendo-se por meio do uso da Internet, a exemplo da utilização da ferramenta Crowdsourcing Constitution na experiência democrática estrangeira. $\mathrm{O}$ fortalecimento do ativismo popular por meio da internet, portanto, pode tornar-se um relevante instrumento de democracia semidireta e de diálogo entre a sociedade e o Estado, aprimorando o regime político democrático.

Contribuições: A principal contribuição desta pesquisa é trazer à tona, por meio de uma discussão sobre a crescente - e democrática - participação popular na Internet, a reiterada necessidade de garantir-se uma efetiva educação por intermédio da informação, e não através da mera manipulação de massas pela desinformação. Com o crescimento da participação na internet, o povo passa a ter impactos diretos na política, o que se intensifica diante da facilidade de acesso à informação e ao diálogo, possibilitados por novos fóruns e palcos virtuais de debate, que podem, agora, pautar diretamente não apenas nas decisões dos poderes constituídos, como também na própria escolha dos representantes do povo.

PALAVRAS-CHAVE: Internet; instrumento; ativismo popular; democracia. 


\begin{abstract}
Objective: To analyze Internet as a relevant instrument of popular activism, capable of strengthening the democratic political regime, enabling a nascent popular activism that opens new frontiers, among them the perspective of greater popular mobilization, as well as a more effective interference in the formation of public opinion.

Methodology: The work was guided by a dogmatic legal research, using the deductive method, developed through bibliographic research, mainly through specialized books and journal articles.

Results: It can be stated, as a conclusion of this research, that semi-direct democracy represents an opening for popular activism, which has been strengthened through the use of Internet, such as the use of the Crowdsourcing Constitution tool in foreign democratic experience. The strengthening of popular activism through Internet, therefore, can become a relevant instrument of semi-direct democracy and dialogue between society and the State, enhancing the democratic political regime.
\end{abstract}

Contributions: The main contribution of this research is to bring to light, through a discussion about the growing - and democratic - popular participation in Internet; the repeated need to ensure effective education through information rather than mere mass manipulation through misinformation. With the growth of participation in the Internet, people have direct impacts on politics, which intensifies in view of the ease of access to information and dialogue, made possible by new forums and virtual stages of debate, which can now apply directly not only on the decisions of the constituted powers, as well as on the very choice of the representatives of the people.

KEYWORDS: Internet; instrument; popular activism; democracy.

\title{
INTRODUÇÃO
}

Atualmente, verifica-se o surgimento de um ativismo popular, que vem se fortalecendo por meio do uso da internet, instrumento que passa a possibilitar uma maior mobilização popular e uma mais efetiva interferência na formação da opinião pública. Esse ativismo popular apresenta-se como um relevante instrumento de fortalecimento da democracia, pois permite o diálogo entre o povo e as instituições democráticas.

No presente artigo, será constatado que essa participação direta do povo na política vem se intensificando diante da facilidade de acesso à informação e ao diálogo por meio da internet. Assim, serão apresentadas breves noções sobre a democracia 
semidireta para, em seguida, apontar o uso da ferramenta Crowdsourcing Constitution na experiência democrática estrangeira. Após, será indicado o papel das mídias digitais na mobilização social e no avanço do ativismo e, por fim, analisar-se-á a necessidade de o fortalecimento do ativismo popular na esfera pública ser livre pela educação, e não manipulado pela desinformação, para que, de fato, torne-se um relevante instrumento de democracia semidireta e de diálogo entre a sociedade e o Estado.

\section{A DEMOCRACIA SEMIDIRETA COMO ABERTURA PARA O ATIVISMO POPULAR}

Muitos consideram utópica a ideia de democracia, por considerar que o povo seria incapaz de exercer uma participação consciente na sociedade. Rousseau destaca a fragilidade da democracia ao mencionar que a vontade geral pode errar e há muitas vezes "grande diferença entre a vontade de todos e a vontade geral: esta olha somente $o$ interesse comum, a outra o interesse privado, e outra coisa não é senão a soma de vontades particulares". Nessa perspectiva, a deliberação do povo, suficientemente informado, sem qualquer comunicação entre si, resultaria na vontade geral do grande número de pequenas diferenças e essa deliberação, apesar de boa, não seria a vontade geral, mas tão-somente a opinião particular (ROUSSEAU, 2002¹).

Nuno Miguel Miranda Ferreira, analisando criticamente o conceito clássico de democracia, segundo a teoria Schumpeteriana, aponta "a democracia como a luta pelos votos, negando subsequentemente a importância do conceito clássico de soberania popular" e conclui que a democracia deve ser analisada sob os seguintes pressupostos (FERREIRA, 2015):

1. Não existe o chamado bem comum, isso pelo simples facto de que, para indivíduos, grupos e classes diferentes, o bem comum significa coisas diferentes; 2 . O chamado governo pelo Povo é uma ficção: o que existe, na realidade, ou pode existir, é o governo do povo; 3 . O governo é exercido por elites políticas; 4. Essas elites competem no mercado político pela preferência

${ }^{1}$ Capítulo III do Livro II. 


\begin{abstract}
dos eleitores; 5. A concorrência no mercado político, tal como no mercado económico, é imperfeita, isto é, oligopólica; 6 . Os partidos políticos e eleitores actuam no mercado político de maneira semelhante á actuação das empresas e consumidores no mercado económico; 7. O voto é a moeda através da qual o eleitor compra os bens políticos oferecidos pelos partidos; 8. A soberania popular, embora não seja nula, é reduzida, visto que são as elites políticas que propõem os candidatos e as alternativas a serem escolhidas pelo eleitor; 9. O objectivo primordial dos partidos políticos é conquistar e manter o poder. A realização do bem comum é um meio para atingir este objectivo; 10 . A necessidade de maximizar votos impede que os partidos e os políticos sirvam exclusivamente os seus interesses de grupo ou de classe. Como diz Bobbio, os controladores são controlados.
\end{abstract}

Numa perspectiva otimista sobre a democracia, Dalmo de Abreu Dallari, numa perspectiva otimista, entende que o "Estado Democrático é um ideal possível de ser atingido", desde que seja eliminada a rigidez formal da noção de democracia para que a democracia atenda à concepção de valores fundamentais variáveis de povo para povo e de época para época (DALLARI, 2016, p. 302-305).

Há três modalidades básicas de democracia na história das instituições políticas: a democracia direta, a democracia indireta e a democracia semidireta. A democracia direta, cujo berço ocorreu na Grécia, tem como característica principal o exercício direto e imediato do poder político pelo povo (BONAVIDES, 2016, p. 288).

A democracia indireta (ou representativa) é caracterizada pela presença do sistema representativo, em que o povo escolhe seus representantes pelo voto para governar. Montesquieu, sobre essa modalidade de democracia, afirma que o povo não tem aptidão para discutir as questões públicas, "fato que constitui um dos grandes inconvenientes da democracia", mas, por meio de seus representantes, o povo pode discutir tais questões e exercer o poder legislativo (MONTESQUIEU, 2007, p. 168).

Já a democracia semidireta é a modalidade que tenta aproximar a democracia representativa à democracia direta, pois a transferência da vontade popular é feita apenas parcialmente, diante da existência de institutos que permitem uma efetiva intervenção direta do povo (BONAVIDES, 2016, p. 288-300).

Assim, a democracia semidireta é um regime político democrático que combina a representação política com institutos de democracia direta. Os instrumentos de democracia semidireta possuem limitações formais e materiais e exigem uma "formação social consistente, em toda sua complexidade, agindo como 
mecanismo indutor e controlador, impetrando meios de freios e contrapesos, de accountability, nesse via de exercício da cidadania, afora o tripé dos Poderes constituídos" (GARCIA, 2005, p. 20).

Os principais institutos de democracia semidireta são as consultas populares, a iniciativa popular, o veto popular e o direito de revogação.

As consultas populares são institutos que visam aumentar o poder decisório dos eleitores, ao permitir que, além de eleger seus representantes, os eleitores também decidam sobre certas questões. Por meio dessas consultas, o eleitorado é convocado às urnas para opinar favoravelmente ou contrariamente a uma proposta. No Brasil, as consultas populares são gênero do qual são espécies o plebiscito e o referendo, que se diferenciam em razão do momento em que são realizadas as consultas, sendo o plebiscito uma consulta prévia ao eleitorado em relação à tomada de uma decisão, enquanto o referendo é uma consulta ao eleitorado feita posteriormente à tomada da decisão (SGARBOSSA; IENSUE, 2018, p. 503-505).

Bobbio aponta o referendo como o único instituto de democracia direta de efetiva aplicabilidade na maior parte dos Estados de democracia avançada, representando um expediente extraordinário para circunstâncias extraordinárias, em razão da dificuldade prática de consultar o povo pelo voto a cada tomada de decisão. Segundo o referido autor, o referendo coloca os problemas sob a forma de excludência, de escolha forçada entre duas alternativas, circunstância que favorece o choque, sendo, pois, é mais adequado para dirimir controvérsias sobre princípios do que para resolver conflitos de interesse (BOBBIO, 1986, p. 9 e 42-45).

A iniciativa popular é um instrumento por meio do qual uma determinada parcela do eleitorado pode apresentar uma proposta de lei ou de emenda à Constitucional para apreciação pelo Poder Legislativo, ou seja, trata-se de mecanismo de proposta legislativa de origem popular (SGARBOSSA; IENSUE, 2018, p. 509).

$O$ veto popular é mecanismo de democracia semidireta pelo qual o povo se opõe à entrada em vigor de uma lei, antes que ela seja aprovada. Por isso, pode ser compreendido como um referendo facultativo, já que, a critério de certa parcela do eleitorado, é realizada uma consulta popular sobre ato legislativo pronto e acabado (Idem, p. 512-515). 
Por fim, o direito de revogação (recall) "consiste na atribuição ao povo da faculdade de retirar uma autoridade do cargo por ela ocupado, normalmente eletivo", ou seja, consiste na capacidade do eleitorado de retirar o mandato de um representante eleito ou nomeado antes de seu término (Idem, p. 515).

A Constituição Federal de 1988 adota a democracia semidireta, pois estabelece que todo o poder emana do povo, que o exerce por meio de representantes eleitos ou diretamente. Assim, a soberania popular, além de ser exercida pelo sufrágio universal e pelo voto direto e secreto, é realizada mediante plebiscito, referendo e iniciativa popular, conforme previsão do art. 14 da $\mathrm{CF} / 88$. A iniciativa popular de

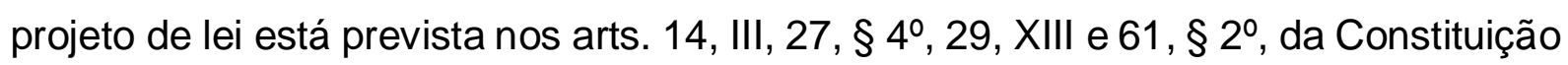
Federal e regrada pela Lei oำ 9.709/98, não havendo previsão de iniciativa popular de emenda constitucional. Por sua vez, a autorização de referendo e a convocação de plebiscito são de competência exclusiva do Congresso Nacional (arts. 14, I e II, e 49, $\mathrm{XV}$, da CF/88).

No Brasil, é tímido o uso do plebiscito e do referendo, destacando-se a capacidade de iniciativa popular e a apresentação formal por meio da "legislação participativa" como mecanismos para construção de uma cultura popular de democracia semidireta. A legislação participativa, entendida como mais um instituto de democracia semidireta, surgiu, inicialmente, na Câmara dos Deputados, e, após, no Senado Federal, por meio da criação da Comissão Permanente de Legislação Participativa (CLP), que autoriza que entidades da sociedade social organizada apresentem ao Legislativo proposituras de lei, por meio de procedimentos céleres, podendo-se afirmar que a CLP avançou, sobremaneira, em relação à iniciativa popular constitucional, inclusive porque (GARCIA, 2005, p. 18-20):

Diferentemente da previsão constitucional de iniciativa, as sugestões legislativas poderão ser apresentadas diretamente à Comissão por associações e órgãos de classe, sindicatos, organizações nãogovernamentais, demais entidades organizadas da sociedade civil e mesmo órgãos oficiais que disponham, em seus conselhos, paridade de representação entre civis e servidores. Bastando, para isso, a apresentação de documentos que confirmem a atuação e o registro da entidade. 
A participação direta do povo na política vem se intensificando diante da facilidade de acesso à informação e ao diálogo por meio da internet, que permite a comunicação via mídias digitais, apesar dos entraves da distância física entre os interlocutores. Sobre a relevância da internet na democracia, importante destacar o uso da ferramenta Crowdsourcing Constitution.

\section{A RELEVÂNCIA DA INTERNET NA DEMOCRACIA: A FERRAMENTA CROWDSOURCING CONSTITUTION}

Atualmente, é fácil verificar que a revolução tecnológica causa significativos efeitos em várias áreas de interesse da sociedade, por facilitar o acesso à informação, permitir a liberdade de expressão e viabilizar o conhecimento de fatos a nível mundial e de forma imediata, de modo que a realidade virtual minimiza os problemas decorrentes da distância e do tempo.

O espaço virtual, que inclui desde redes sociais até sites de conteúdo genérico, passou a representar um importante instrumento de comunicação que exige uma constante adaptação da sociedade a essa nova realidade. O mundo jurídico também vem sentido essa necessidade de adaptação às novas tecnologias.

Nesse contexto, é que surge a ferramenta denominada Crowdsourcing que (CONTIPELLI, 2013, p. 2377-2380):

[...] genericamente, consiste em uma plataforma de produção coletiva e democrática de conhecimentos, que tem por finalidade a utilização do espaço virtual, com a formação de uma comunidade on-line de pessoas, para solucionar os mais variados tipos de problemas, promovendo colaboração e compartilhamento de ideais entre seus participantes como forma de alcançar as respostas e os resultados esperados. Em termos literais, o Crowdsourcing pode ser traduzido como "colaboração em massa", o que explica em grande parte o funcionamento dessa ferramenta tecnológica de inteligência coletiva, haja vista que se instrumentaliza com a propositura a um grupo de voluntários dotados de diferentes capacidades (dinheiro, técnica, informação, entre outras) a realização de um determinado empreendimento, que terá como resultado benefícios recíprocos para todos participantes, que envolvem desde conteúdo econômico até mesmo uma mera satisfação pessoal, enquanto o Crowdsourcer (idealizador do projeto) utilizara o resultado conjunto e final do empreendimento. Um dos melhores exemplos de funcionamento e sucesso do modelo proposto pelo Crowdsourcing é o 


\begin{abstract}
conhecido Wikipedia (...). Portanto, as possibilidades de aplicação do "Crowdsourcing" são infinitas, dentre as quais se pretende destacar sua utilização no campo de interesses públicos, como instrumento virtual de manifestação dos cidadãos, para, se valendo da ideia de colaboração em massa e participação política, possibilite a formação de ações estatais dirigidas ao atendimento de suas reais necessidades, além é claro de um maior controle da gestão pública, o que se compatibiliza com os conceitos de legitimação democrática anteriormente apresentada. No Brasil, já existem muitos sites especializados que promovem a colaboração ativa e fiscalização da vida pública, que estimulam e permitem aos cidadãos expressar suas opiniões sobre projetos de lei, encaminhar reclamações ao Poder Público e até mesmo propor a realização de serviços e obras públicas em suas cidades, participando diretamente das ações de governo.
\end{abstract}

A colaboração coletiva constitucional (Constitutional crowdsourcing) é um caso especial de colaboração coletiva (crowdsourcing) que ocorre por meio de publicação on-line dos esboços da Constituição para permitir o envolvimento das pessoas no processo de redação do texto constitucional. Essa ferramenta teve sua primeira experiência em 2011 pelos membros do Conselho Constitucional da Islândia, que publicaram doze projetos de constituição em uma página web e no Facebook para possibilitar a participação popular na elaboração da Constituição. Os membros do Conselho receberam mais de 16.000 sugestões por meio de correios eletrônicos e redes sociais, responderam a algumas delas, atualizaram os esboços dos projetos de Constituição e, após, fizeram uma versão final com as preferências contidas nas sugestões dos cidadãos quanto à forma e ao conteúdo do texto constitucional. Contudo, apesar dessa versão ter sido submetida a um referendo não vinculante, que obteve a aprovação de mais de $2 / 3$ dos eleitores, o Parlamento nunca adotou o projeto resultante do referido processo (BERNAL, 2018, p. 187-188). Estratégia similar também foi adotada pela Assembleia Constituinte do Egito em 2011, pelo Comitê de Expertos no Quênia em 2009 e pela Convenção Constitucional da Irlanda em 2012 a 2014 (Idem, p. 187-189).

Atualmente, o Chile passa por um processo de substituição constitucional que adota uma estratégia estruturada de colaboração coletiva (crowdsourcing). Esse processo tido como "aberto à cidadania" incluiu uma participação cidadã em três etapas: o "Encontro", a "Deliberação" e a "Soberania". Na etapa "Encontro", ocorrida entre abril a agosto de 2016, a participação dos cidadãos foi possibilitada pelo preenchimento de um formulário on-line contendo quatro perguntas fechadas e uma 
aberta, além de algumas atividades off-line, como reuniões. Essa etapa "Encontro" foi precedida por uma campanha pedagógica, na qual os cidadãos receberam informações sobre conceitos constitucionais básicos. Em janeiro de 2017, um Conselho de Observadores Cidadãos entregou ao então Presidente os resultados sistematizados do "Encontro", em um relatório intitulado "Bases Cidadãs", o qual será utilizado para preparar o esboço do projeto de Constituição, que deve ser apresentado ao Congresso brevemente. Na etapa "Deliberação", haverá uma participação popular na Assembleia Constituinte e, por fim, na "Soberania", a participação popular ocorrerá depois que a instituição competente deliberar e promulgar a nova Constituição, mediante um plebiscito (Idem, p. 190-192).

Com efeito, o Crowdsourcing Constitution pode ser compreendido como uma Constituição criada ou modificada com a utilização do espaço virtual, em que se estabelece uma rede de cooperação aberta para participação direta e ativa dos cidadãos na determinação das disposições normativas do texto constitucional ou nas decisões políticas que promovem sua interpretação e aplicação. É, portanto, uma ambiciosa forma de ampliação do funcionamento da representação política direta com o auxílio do mundo virtual (CONTIPELLI, 2013, p. 2384).

Assim, a redação colaborativa constitucional (constitutional crowd-drafting) representa uma ferramenta para fortalecer a legitimidade democrática dos processos de construção constitucional, por permitir a participação popular de indivíduos e grupos em deliberações e nas decisões relacionadas ao conteúdo da Constituição, criando um processo aberto de participação e inclusão dos cidadãos, pelo uso das novas tecnologias (BERNAL, 2018, p. 232-233).

O Crowdsourcing Constitution representa uma ferramenta de participação direta do povo na política por meio da comunicação via mídias digitais. Essa influência da interação humana nas redes sociais sobre a ordem democrática constitucional, mediante sua participação na produção de textos normativos ou na interpretação constitucional permite afirmar que existe um avanço do ativismo popular no âmbito do diálogo entre sociedade e Estado. 


\section{O PAPEL DA INTERNET NO AVANÇO DO ATIVISMO POPULAR}

O ativismo popular (ou ativismo social) envolve processos de manifestação popular sobre diversas dimensões (políticas, sociais, culturais, ambientais e sentimentais). Atualmente, esse ativismo popular vem se fortalecendo, havendo uma grande presença de grupos nas ruas, no Congresso e nas redes sociais proclamando por melhorias ou reivindicando a efetivação de seus direitos (BATTEZINI; REGINATO, 2016, p. 177).

Há quem utilize a terminologia constitucionalismo popular como movimento em favor da "restituição" ao povo da tarefa de interpretação e aplicação da Constituição, por intermédio de sua atuação nas ruas, pelo voto popular ou pelo trabalho de seus representantes no Parlamento (ARAÚJO, 2017, p. 69).

Esse crescimento da mobilização popular sobre o poder constituinte e a hermenêutica constitucional decorre do uso das redes sociais. Isso porque "um indivíduo, sozinho, é incapaz de proclamar pela efetividade de seus direitos", sendo necessária uma organização conjunta que tenha a capacidade de mobilizar grupos com os mesmos interesses envolvidos. Essa mobilização, quando realizada pela internet, representa um novo paradigma social que pode ser denominado como ativismo digital, midiático, em rede ou ainda ciberativismo. "O ativismo realizado pelos canais de comunicação tecnológicos diferencia-se dos demais pelo seu alcance, pois utiliza as ferramentas cibernéticas para promover ações que visam o mesmo objetivo", sendo possível, através do uso da internet, militar por causas diversas, a exemplo dos excessos praticados pelo Poder Público. $O$ ativismo popular, conectado a essa nova sociedade de informação, representa uma evolução no papel democráticoconstitucional e na liberdade de expressão, porque não depende de instituições mediadoras (BATTEZINI; REGINATO, 2016, p. 177-178).

Diante desse papel das mídias digitais na mobilização social, é possível afirmar que vem avançando o ativismo popular, com força suficiente para questionar as decisões tomadas no âmbito dos três poderes. 


\section{O ATIVISMO POPULAR LIVRE PELA EDUCAÇÃo COMO RELEVANTE INSTRUMENTO DE DEMOCRACIA SEMIDIRETA E DE DIÁLOGO ENTRE A SOCIEDADE E O ESTADO}

O atual Estado Constitucional de Direito está pautado na supremacia da Constituição, a qual consagra e amplia os direitos fundamentais e estabelece a teoria da separação dos poderes como uma limitação do poder pela divisão de funções. Essa atuação harmônica entre os poderes constituídos constitui instrumento para consecução dos fins do Estado. Em suas origens, a teoria dos freios e contrapesos de Montesquieu surgiu para limitar o poder dos governantes, porém acabou por possibilitar uma supremacia do legislador, mas, com a consagração de textos constitucionais como limite ao legislador, caminhou-se para uma abertura da possibilidade de supremacia do Judiciário.

Apesar da importância da divisão de funções para limitação do poder, devese sempre considerar que, no regime democrático, todo poder emana do povo, que o exerce diretamente (democracia direta) ou por meio de seus representantes eleitos (democracia indireta ou representativa), ou ainda por meio da democracia semidireta, regime político que agrega à democracia representativa instrumentos de participação direta do povo na tomada de decisões do Estado.

Nosso ordenamento jurídico consagra a democracia semidireta ao prever, além da eleição dos membros do Poder Executivo e Legislativo, os institutos das consultas populares (plebiscito e referendo) e da iniciativa popular. Saliente-se que os membros do Judiciário não são eleitos, mas sim nomeados, no caso da magistratura de carreira, sempre após concurso público de provas e títulos (art. 93, I, da CF/88), enquanto a nomeação dos demais magistrados é efetuada pelo Presidente da República (art. 84, XVI, da CF/88) ou pelo Governador do Estado, observadas as regras do texto constitucional.

A despeito da previsão constitucional de institutos da democracia semidireta, ainda se apresenta tímido o uso das consultas populares (plebiscito e referendo) e da iniciativa popular. Contudo, o ativismo popular, que vem se fortalecendo em razão do uso das mídias digitais contidas na internet, constitui um legítimo meio limitação do 
poder que pode ser considerado como uma ferramenta da democracia semidireta, especialmente porque viabiliza um efetivo diálogo entre a sociedade e os poderes estatais.

Nesse contexto, a internet surge como um importante canal de disseminação do ativismo popular, pois vem se tornando usual o desencadeamento, pelas redes de comunicação, de movimentos de insatisfações por parte da população decorrentes da má administração dos agentes estatais. A população, por meio desses mecanismos digitais, é capaz de promover mudanças significativas nas estruturas do poder (Idem, p. 182).

O uso da internet amplia a possibilidade de participação popular no funcionamento do Estado, pois, diante do avanço do ativismo popular, permite o diálogo entre os representantes do povo e o povo. Nesse contexto, o papel das mídias digitais na formação da opinião pública e na mobilização do ativismo popular torna-se extremamente relevante para funcionar como um mecanismo de freio e contrapesos diante de abusos dos detentores de poder. Contudo, deve-se destacar a "fragilidade" do ativismo popular diante do problema da falta de acesso à informação, decorrente do descaso do Estado para com a educação e da falta de acesso aos meios de comunicação digital, bem como diante do perigo da desinformação, decorrente da propagação de informação falsa com o propósito de confundir ou induzir a erro o interlocutor (fake news).

Sobre essa questão, ressalte-se a já mencionada iniciativa do Chile no processo de substituição constitucional, que, em sua estratégia estruturada de colaboração coletiva (crowdsourcing), teve sua primeira etapa ("Encontro") precedida de uma campanha pedagógica, na qual os cidadãos receberam informações sobre conceitos constitucionais básicos.

Esse exemplo indica que existe uma necessidade de acesso à informação sobre o funcionamento do Estado e da política e sobre os meios de controle das autoridades públicas. Ademais, há uma necessidade de aprimoramento do ativismo popular por meio de uma conscientização acerca dos reais fatos que envolvem o problema objeto de questionamento. Nesse aspecto, o Estado tem uma facilidade de 
difundir pelos diversos meios de comunicação (rádio, TV, internet, etc) a educação para a cidadania.

Contudo, tal como ocorre na alegoria da caverna de Platão (PLATÃO, 201 ${ }^{2}$ ), o Estado, por meio dos detentores de poder, prefere manter a maioria dos cidadãos como prisioneiros, sem acesso à educação e à verdade, mantendo-os, ilusoriamente, com uma visão de mundo do ignorante, acorrentados a falsas ideias e, por isso, inertes na busca pela liberdade, até mesmo em razão do perigo que essa liberdade representa não apenas para os detentores de poder como para o próprio exprisioneiro.

Paulo Freire explica que a teoria antidialógica das elites dominadoras, em que se falseia o mundo para melhor dominar as massas populares e garantir a continuidade de seu poder, é opressora. Isso porque, do ponto de vista da dominação, a única forma de pensar certo é jamais permitir que as massas pensem certo, por isso que a manipulação, na teoria antidialógica, tem a função de anestesiar as massas populares para que não pensem. Essa cultura antidialógica das elites dominadoras deve ser combatida com uma teoria dialógica, de caráter revolucionário-libertadora, capaz de conscientizar as pessoas acerca da ideologia opressora e de permitir a libertação desta classe por meio da educação libertadora. $\mathrm{Na}$ educação libertadora revolucionária, não existe um polo dominador e um polo dominado, pois visa superar essa dicotomia por meio da educação crítica e libertadora, diante da constatação de que "seria uma ingenuidade esperar das elites opressoras uma educação de caráter libertário" (FREIRE, 1987, p. 70-107).

O surgimento e fortalecimento do ativismo popular na esfera pública, desde que livre pela educação e não manipulado pela desinformação, pode se tornar um relevante instrumento de democracia semidireta e de diálogo entre a sociedade e o Estado, capaz de efetivar os ideais democráticos e republicanos, em razão de sua capacidade de direcionamento das atividades estatais e de limitação dos abusos das autoridades estatais. Deve-se salientar que esse mesmo ideal para a construção de verdadeiro ativismo popular se aplica ao fenômeno da representação política, embora

${ }^{2}$ O mito da alegoria da caverna consta no Livro VII da obra. 
a realidade demonstre esta como uma luta do detentor do poder pela conquista de voto para sua manutenção no poder.

Assim, evidencia-se o surgimento de um ativismo popular que, não manipulado pela desinformação e livre pela educação, tem uma enorme potencialidade de garantir um efetivo governo do povo (ideal democrático) para o bem comum (ideal republicano), inclusive como legítimo mecanismo de contenção dos abusos de autoridades estatais capaz de auxiliar na atuação independente e harmônica entre os poderes.

\section{CONCLUSÃO}

A democracia semidireta, por permitir, além da representação política, a participação direta do povo na tomada das decisões políticas, representa uma abertura para o ativismo popular, o qual vem se fortalecendo por meio do uso da internet.

A relevância da internet na democracia restou constatada por meio da utilização da ferramenta Crowdsourcing Constitution na experiência democrática estrangeira, considerando que o espaço virtual já passa a ser usado como uma rede de cooperação aberta para participação direta e ativa dos cidadãos na criação das normas do texto constitucional ou nas decisões políticas decorrente da interpretação e aplicação da Constituição.

É de enorme importância, ainda, o papel da internet no avanço do ativismo popular, diante do uso das mídias digitais na mobilização social para questionar as decisões tomadas no âmbito dos três poderes, permitindo um efetivo diálogo entre 0 povo e as instituições democráticas, com o conseqüente fortalecimento da democracia.

Esse o fortalecimento do ativismo popular por meio da internet, desde que livre pela educação e não manipulado pela desinformação, pode se tornar um relevante instrumento de democracia semidireta e de diálogo entre a sociedade e o Estado, aprimorando o regime político democrático. 


\section{REFERÊNCIAS}

ARAÚJO, André Carias de. Diálogos institucionais como instrumento de desenvolvimento de uma jurisdição constitucional democrática. Dissertação (Mestrado em Direito), Programa de Pós-Graduação em Direito da Universidade Federal do Paraná, Curitiba, 2017. Disponível em: $<$ https://acervodigital.ufpr.br/bitstream/handle/1884/47703/R\%20-\%20D\%20\%20ANDRE\%20CARIAS\%20DE\%20ARAUJO.pdf?sequence=1 \&isAllowed=y >. Acesso em: 18/10/18.

BATTEZINI, Andy Portella; REGINATO, Karla Cristine. O ativismo popular e o papel das mídias digitais: reflexos de um novo modelo de exercer democracia no cenário contemporâneo e seus impactos na esfera política. Revista de Direito Brasileira, São Paulo-SP, v. 15, n. 6, p. 173-184, set./dez., 2016. Disponível em: <http://www.indexlaw.org/index.php/rdb/article/view/2991/2763>. Acesso em: 18/10/18.

BERNAL, Carlos. Pode a colaboração coletiva constitucional (constitutional crowdsourcing) fortalecer a legitimidade dos processos de construção constitucional? Revista Brasileira de Estudos Políticos, Belo Horizonte, n. 116, pp. 185-246, jan./jun., $2018 . \quad$ Disponível em: <https://pos.direito.ufmg.br/rbep/index.php/rbep/article/view/571/452>. Acesso em: 20/10/18.

BOBBIO, Norberto. El futuro de la democracia. Trad. de José F. Fernández Santillán. $2^{2}$ ed., México: Fondo de Cultura Económica, 1986.

BONAVIDES, Paulo. Ciência política. 23aㅡ ed. São Paulo: Malheiros, 2016.

CONTIPELLI, Ernani. Crowdsourcing Constitution: solidariedade e legitimação democrática na Pós-modernidade. Revista Eletrônica Direito e Política, Programa de Pós-Graduação Stricto Sensu em Ciência Jurídica da UNIVALI, Itajaí, v. 8, n. 3, 3o quadrimestre de 2013.2 Disponível em: https://siaiap32.univali.br/seer/index.php/rdp/article/viewFile/5452/2877>. Acesso em: 20/10/18.

DALLARI, Dalmo de Abreu. Elementos de teoria geral do Estado. 33르 ed. São Paulo: Saraiva, 2016.

FERREIRA, Nuno Miguel Miranda. O conceito de democracia segundo Joseph Schumpeter. Disponível em: <http://empreende.org.br/pdf/Democracia\%20e\%20Participa\%C3\%A7\%C3\%A3o/O \%20conceito\%20de\%20democracia\%20segundo\%20Joseph\%20Schumpeter.pdf>. Acesso em: 10/07/15.

FREIRE, Paulo. Pedagogia do oprimido. 17ª ed. Rio de Janeiro: Paz e Terra, 1987. 
GARCIA, Alexandre Navarro. Democracia semidireta: referendo, plebiscito, iniciativa popular e legislação participativa. Revista de Informação Legislativa, Brasília, a. 42, n. 166, abr./jun., 2005.2 Disponível em: <https://www12.senado.leg.br/ril/edicoes/42/166/ril_v42_n166_p9.pdf>. Acesso em: 19/10/18.

MONTESQUIEU, Charles de. Do espírito das leis. Trad. Jean Melville. São Paulo: Martin Claret, 2007.

PLATÃO. A República. Introdução, tradução e notas de Maria Helena da Rocha Pereira. 9ª ed. Lisboa: Fundação Calouste Gulbenkian, 2001.

ROUSSEAU, Jean-Jacques. O Contrato Social. Tradução: Rolando Roque da Silva. Edição eletrônica: Ed. Ridendo Castigat Mores (www.jahr.org). Publicado em: 04/01/2002. Disponível em: $<$ http://www.dominiopublico.gov.br/pesquisa/DetalheObraForm.do?select_action=\&c o_obra=2244>. Acesso em: 11/08/18.

SGARBOSSA, Luís Fernando; IENSUE, Geziela. Teoria do Estado Moderno e Contemporâneo: fundamentos do Direito Público e do Direito Constitucional. $1^{1} \stackrel{a}{ }$ ed., Campo Grande: Instituto Brasileiro de Pesquisa Jurídica, 2018. 